\title{
Application Of Path-Goal Leadership Theory And Learning Theory In A Learning Organization
}

\author{
Bayan Yousef Farhan, Al Ain University of Science and Technology, UAE
}

\begin{abstract}
This paper used learning theory and path-goal theory to propose a learning leadership model. The practical side of these two theories is suitable for this proposed model, its agenda, and its tools for improving organizational learning. The model is based on the assumption that leaders need to develop their competences and the competences of subordinates by creating a continuous learning process through sharing, exchanging, and improving knowledge and experiences. The model states that learning leaders act as facilitators of the organizational learning process and adopt the right attitude to motivate subordinates for learning by removing obstacles and creating a learning culture.
\end{abstract}

Keywords: Learning Leaders; Learning Organizations; Path-Goal Theory

\section{INTRODUCTION}

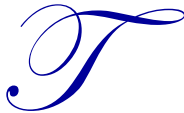

he ongoing changes in the business environment represent significant challenges for leaders and their organizations. Operating in a highly competitive and changing work environment makes competent leaders an important asset for an organization. Leaders' competences are, arguably, a key factor for establishing a successful organization in a given competitive environment. Thus, while enhancing leaders' ability to understand the internal and external changing work environments is critical, they also need to improve their competitiveness by improving their way of thinking and how they do things. At the institutional level, according to Wen (2014), "the ability to learn faster than the competitors is the only sustainable competitive advantage" (p. 290). Thus, it is leaders' responsibility is to enhance the competitiveness of their organizations and their ability to compete in growing competitive markets. Competences, for the purpose of this paper, is defined as the extent to which leaders are willing to improve their personal leadership skills and knowledge to cover the gap between their current leadership competences and the required ones.

The aim of this paper is to propose a learning leadership model that might facilitate learning within an organization. The application of learning theory and path-goal theory is the base for proposing this model. The key argument is that it would be hard to encourage and facilitate learning in an organization without a learning leader who believes that there is an ongoing need for learning at the personal and the organizational levels. The concept of a learning leader is proposed in this paper and was not highlighted before in literature. The 28 leadership styles were discussed in literature without highlighting learning leadership style and its role in improving organizations (Hussain \& Hassan, 2016):

These styles include authoritative style, laissez-faire style, democratic style, transactional style, transformational style, team oriented style, coercive style, visionary style, coaching style, affiliative style, pacesetting style, servant leadership style, shared leadership style, directive style, participative style, supportive style, achievement oriented style, tolerant style, consideration style, initiating structure style, task oriented style, relationship oriented style, telling style, selling style, consultative style, leaders-member exchange (LMX) style, authentic leadership style, and integrity leadership style. (p. 416).

The literature also ignores the importance of leaders' learning attitude, and the tools that learning leadership should adopt in order to improve learning organizations. Some studies (Fauske \& Raybould, 2005) ignore the role of learning leadership and asserted that "organizations learn through individuals learning of its members" (, p. 23). Others 
(Kramlinger, 1992) described learning organizations as "a large body of aligned individuals (such as corporation) whose members at all levels spontaneously learn and innovate in ways that promote the well-being and mission of the organization" (Kramlinger (1992) p. 48).

In this paper, learning leadership is defined as a lifelong learning attitude which allows leaders to improve themselves and facilitate learning for their subordinates. The idea of learning leadership is based on the assumption that leaders need to develop their competences and the competences of subordinates by creating a system that supports learning to improve and exchange knowledge and experiences. The paper also proposes that leadership styles (supportive, participative, directive, and achievement), are emphasized as tools for learning leaders to encourage learning across organizations. The interaction between leaders and subordinates can serve the purpose of understanding subordinates' attitudes and feelings about learning which can help leaders to respond to their expectations.

The first part of this paper discusses the proposed theoretical framework. The second and third parts explain the application of learning theory and path-goal theory as a base to propose a learning leadership model. The application of these theories explains the suggested agenda and tools for learning leaders to improve organizational learning. The fourth section in this paper, explains the importance of learning leadership for a learning organization. Finally, the closing section discusses the adoption of a learning leadership approach.

\section{THE THEORETICAL FRAMEWORK}

The theoretical framework of this paper is closely related to learning theory and path-goal theory. The framework was developed based on the assumption that leaders need to increase the effectiveness of the learning process in their organizations by being flexible to adopt the needed leadership styles. Based on the learning theory, "learning is mostly related to knowledge created through the transformation of experience" (Kolb, 1984, p.38). The interaction between leaders and subordinates, and the organization's culture are essential to improve subordinates' skills and knowledge. At the same time, the foundation of the path-goal theory was highlighted initially by House (1971) who focused on studying the effect of leaders' behaviors (supportive, directive, achievement-oriented, and participative behavior) on subordinates' motivation and performance. According to House, the effectiveness of leadership depends on the behavior of a leader and if it compensates for subordinates lacks and if it contributes to subordinates' satisfaction and performance. House stressed that the effects of leadership behavior on subordinates' motivation and satisfaction are contingent in which each of the behaviors are likely to be effective or ineffective.

Path-goal theory, as suggested by Dixon and Hart (2010), suggests such flexible behaviors like "clarification, direction, structure, and rewards" (p. 55). According to the theory, the adoption of path-goal leadership styles allow leaders to "clarify and provide directions for followers, help remove obstacles, and provide encouragement and rewards for goal achievement" (Dixon \& Hart, 2010, p. 55). Considering the suggestions of path-goal theory, this paper argues that learning leaders act as facilitators, and adopt different behaviors to motivate subordinates towards learning by removing obstacles and adopting a learning attitude. This argument is supported by Nahavandi (2014) who suggested that "leader's role is to clear the paths subordinates use to accomplish goals" (p. 80).

The theoretical framework (see below) is developed based on the suggestions that:

1. learning leadership is a key factor in building a learning organization;

2. The adoption of learning leadership model can enhance the learning process, and motivate subordinates through the adoption of different path-goal leadership styles to improve learning in an organization.

3. Learning leadership model supports the development of the organizational structure and strategies that focus on encouraging learning through sharing knowledge, information, and experience. 
Figure 1. Theoretical Framework.

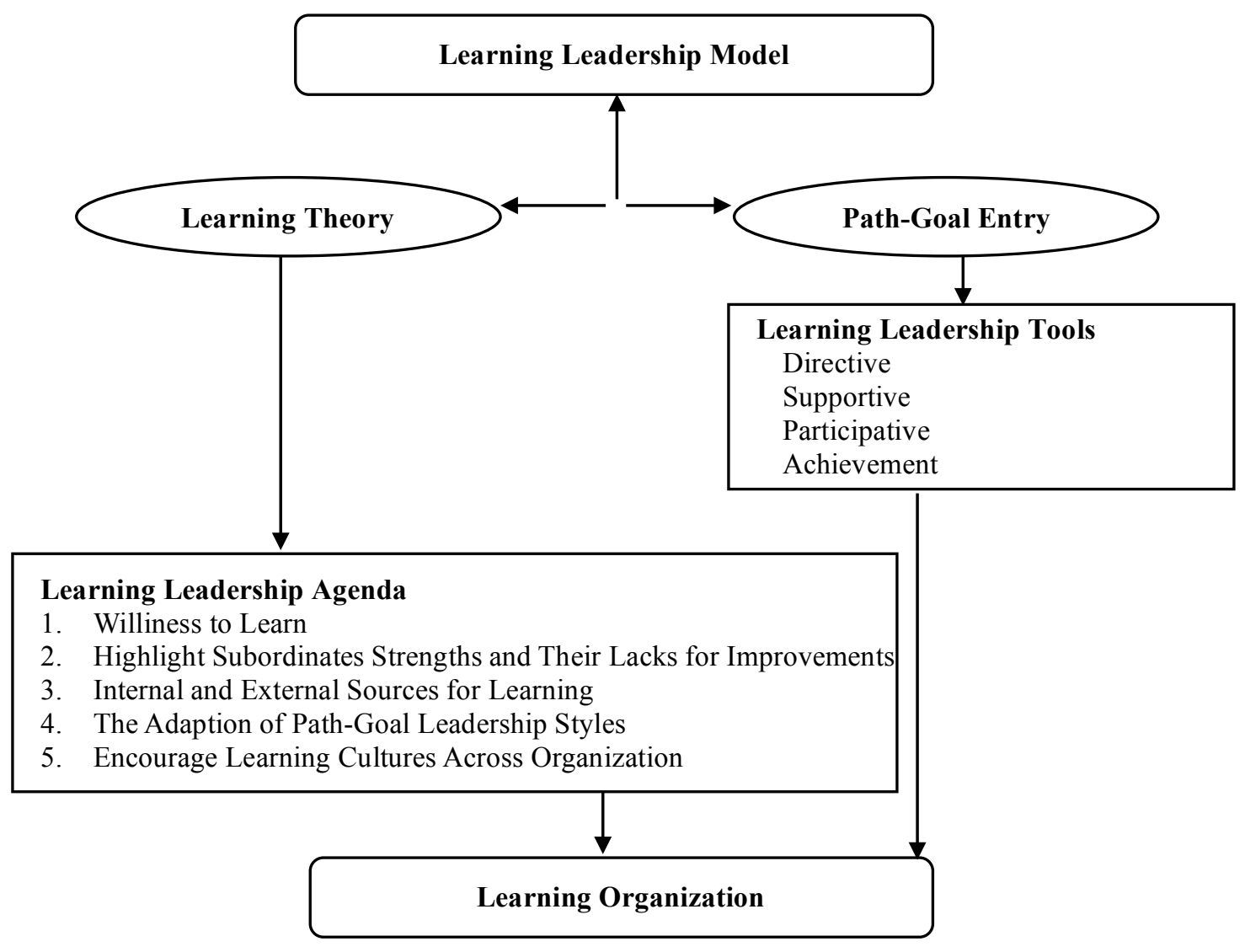

\section{LEARNING THEORY}

Learning theory underlines the importance of sharing knowledge and experience, and how feedback can be seen as a key element in learning process and its role in affecting individuals and groups' development (Hendry, 1996). The feedback process, according to the learning theory, allows understanding and creating shared knowledge, vision, and culture that can influence actions across an organization (Hendry, 1996). In addition, the development of a reward system and relationship can reinforce the learning of new activities (Hendry, 1996). Therefore, one can suggest that learning leaders, not only have to motivate subordinates' learning attitude, but also to be able to learn continuously to protect their knowledge and expertise from being 'downgraded'. Indeed, being well-informed is critical for leaders to survive themselves in their organizations and keep their positions.

\section{The Application of Learning Theory}

The aim of applying learning theory is to propose a learning leadership agenda. The commitment towards learning is the key pillar in learning leadership. To flourish learning obligation, learning agenda should be a regular part of learning leaders' social and professional life. But how leaders can improve the practice of learning and how subordinates become a part of the learning process. These questions are not easy to answer, but to advance learning leadership approach, this paper proposes five foundations that are derived from learning theory to construct and to improve learning leadership. Learning theory is the base for suggesting these five foundations. The reason behind choosing these foundations is that they are related to improving learning attitude across an organization and encouraging the sharing of knowledge and experience. The five foundations are: 
1. Willingness to learn;

2. Highlighting subordinates strengths and their need for improvement;

3. The appreciation of internal and external work environment as sources for learning;

4. The adoption of path-goal leadership styles;

5. Creating a learning culture across the organization by enhancing the attitude of sharing information and cohesiveness through the use of soft abilities like communication, gratitude, and consideration.

The adoption of the previous points allows shaping organizational culture, where learning and the ability to learn are essential parts for the new culture. The 'willingness and abilities to learn' is based on competences that leaders already have. Leaders bring their educational, professional, and cultural backgrounds to their organization. Understanding those backgrounds provide an important starting point to highlight their lack of competences, and identify what needs to be improved. Shedding light on the gap between the current competences and the needed ones become the key point to enhance the willingness for learning in the first stage of the learning process. Indeed, highlighting the importance of knowing self-strengths and weaknesses to build on strengths and overcome weakness can help a learning leader to recognize his/her proficiency to achieve learning objective.

The second point - 'highlights subordinates' strengths and weaknesses'-, leaders need to focus more on subordinates' competences, and their strengths and weaknesses. Without understanding of subordinates' strengths and weaknesses, it is hard to implement an appropriate learning vision and a suitable learning process. In this stage, leaders should encourage the interaction between organizational stakeholders (leaders, employees, and other external professionals). This allows the sharing of information and experience among them, which lead to spread knowledge throughout the organization. Knowledge sharing was emphasized by Pei-Lee and Sun (2012) as a "social interaction culture, involving the exchange of employee knowledge, experiences, and skills through the whole department or organization" (p. 65). In their empirical study, Pei-Lee and Sun found a positive relationship between the two variables of job involvement and job satisfaction and subordinates' knowledge sharing. Further, leadership can influence the organization as a whole since it "includes not only the leaders' actions, but also their thinking, feelings, and the meanings that they and others attach to events in the organization" (Copland \& Knapp, 2006, p. 15).

At the third point - 'appreciation of internal and external work environment' -, leaders can benefit from internal and external organization's stakeholders. Creating a learning environment requires conducting professional learning workshops to enhance learning leadership practices, and their subordinates' learning practices. The idea of doing by learning was carried out by Juceviciene (2015) in her empirical study. Juceviciene stressed that employees are involved into their own practical work which would lead to improve their learning in an organization. She also added that "such work organizations that perform as knowing [learning] organizations, are also interested in having their employees create knowledge while performing their own main work. This knowledge creation takes place in the organizational learning process" (p. 46). Indeed, the aim of the learning leadership is to encourage learning process through the adoption of a strategy that allows working with proficient insiders and outsiders, to benefit from their norms, values, knowledge, and experience. In addition, the adoption of open communication allows improving learning work environment that might reduce conflict, disable resistance, and encourage tolerance for uncertainty and ambiguity.

The fourth point -'the adoption of path-goal leadership styles' - allows learning leaders to adopt appropriate leadership styles in order to motivate subordinates towards the goal of learning. These styles include directive, participative, supportive, and achievement-oriented (Malik, Aziz, \& Hassan, 2014). Based on the flexibility of these styles, the paper argues that learning leaders can adopt different leadership styles to achieve the target of influencing subordinates' learning attitudes. The adoption of path-goal leadership styles helps leaders to "clarify and provide direction for followers, help remove obstacles, and provide encouragement and rewards for goal achievement" (Dixon \& Hart, 2010, p. 55). House (2004) also added that leaders can motivate subordinates by facilitating and clarifying the road to achieve goals. One empirical study (Ojo, 2009) confirmed that the adoption of an appropriate leadership style "has impact on the competitive nature of the organization" (p. 195).

The fifth point - 'encouraging learning culture across the organization' - suggests that learning leaders should consider such actions to create a learning culture. Van Breda-Verduijn and Heijboer (2016) empirically examined how an organizational culture contributes to organizational improvement and innovation. They stressed that a learning 
culture is a key issue for spreading knowledge and continuous learning within organization and can be achieved through the development of professionals. Another empirical evidence (Nasima Mohamed \& Johan, 2013) examined how to create a learning climate and suggested that "learning was regarded as a daily activity and that management could both support and encourage it through their interaction and style" (p. 15). They also added that employees" freedom to express their opinions, and their creativity in doing things without negative consequences will support the creation of learning climate. However, this paper suggests the following actions that leaders can adopt to improve the learning culture within an organization:

1. Communicating their new culture clearly by stating what is important;

2. Supporting the attitude of sharing information and cohesiveness through the use of soft abilities like communication, gratitude, and consideration;

3. Improving people's ability to work together through encouraging interaction and questioning attitudes. Leaders and stakeholders have to work together and exchange information effectively between each other. Therefore, building team-work environment and developing close relationships are important;

4. Rewarding subordinates for their learning attitude.

However, applying a learning leadership agenda requires allocating time and money to serve the purpose of improving learning practices and professional development.

\section{PATH-GOAL THEORY}

Based on path-goal theory, leadership behaviors as a source of influence, can change the attitude, motivation, and behavior of an individual subordinate (Malik et. al., 2014). Path-goal leadership theory requires learning leaders, who are interested in spreading a learning culture to adopt directive, supportive, participative, and/or achievement-oriented behavior. Indeed, learning leaders can adopt one of these behaviors to achieve the goal of influencing subordinates' knowledge and experiences. In addition, the adoption of appropriate style is required to respond quickly to subordinates' expectations, needs, and wants. According to DeCaro (2005), the adoption of appropriate behavior depends on the change in situational factors like organizational culture, task uncertainty, and subordinates' characteristics. Leaders' actions, according to O'Boyle and Cummins (2013), can compensate for any lack that might be shown. This suggests that learning leaders can adopt any of the path goal leadership styles to motivate subordinates to fill the learning gap and improve their learning shortage.

The adoption of path-goal leadership styles by learning leaders allow influencing subordinates' learning attitudes through clarifying the path and removing obstacles, and allowing the goal of improving learning organization to be achieved. The adoption of appropriate style will help subordinates satisfy their needs and accomplish learning goal. According to DeCaro (2005), path-goal theory focuses on "leaders influence[ing] subordinates' perceptions of their work goal, personal goals and paths toward goal attainment" (p. 18).

\section{The Application of Path-Goal Theory}

As mentioned above, the paper uses path-goal leadership styles as tools for learning leadership. "Leadership style appears to be a "practical" tool for answering the ... need for an engaged workforce, particularly since service specificities and high levels of environmental complexity characterize the sector" (Sarti, 2014, p. 213). The aim of using these tools is to motivate subordinates and to enhance their commitments towards learning. The most important tool is the participative style since the adoption of this style allows passing the knowledge within organization, and sharing ideas, opinions, and suggestions. The other tools like supportive, directive, and achievement are also important. A full discussion is provided below.

\section{Participative Leadership Style as a Tool}

Participative style is proposed here as a key tool for progressive movement of learning within an organization. House and Dessler (1974) defined participative behavior as leaders' appreciation of their subordinates' suggestions and opinions. Participative approach was also explained by Linski (2014) who stated that "employees at all levels are encouraged to contribute ideas towards identifying and setting organizational-goals, problem solving, and other 
decisions that may directly affect them" (p. 19). Learning leaders can contribute to learning organization if they motivate subordinates towards learning vision and employ learning resources. This could be done by encouraging communication and information flow between subordinates and leaders at all levels. In addition, using participation as a tool successfully requires subordinates to understand the purpose and the benefits of sharing their knowledge and its effect on their organization. The adoption of this tool by learning leaders can encourage subordinates' inputs and feedback regardless of their position or title, and regardless of their interpersonal conflicts. In an empirical research, Xue, Bradley, and Liang (2011) examined the effect of empowering on knowledge sharing and found that improving participative approach can enhance members' attitudes towards knowledge sharing in organizations. Indeed, the implementation of this tool provides a room for sharing knowledge, moving information and ideas, and allows for learning from own experience and from each other, which in turn would allow for a learning organization to exist. Ford (2006) mentioned that participation process of open communication might encourage power sharing that "enable them to overcome barriers to organizational learning by challenging the status quo" (p. 497).

The participative approach allows for sharing leadership and responsibilities among subordinates (Nahavandi, 2014). According to Ford (2006), leading through facilitating learning goes beyond participating to make decisions and empowering employees. Employing participative tool successfully can encourage building multiple relationships with internal and external stakeholders as sources for learning. By using a participative style as a tool, learning leaders can support learning by encouraging innovation and creativity across organizations through collecting new ideas, suggestions, and solutions. Finally, allowing subordinates to participate might enhance their satisfaction level that might lead to enhance their performance. An Empirical study by Sarti (2014) has supported this statement and concluded that the adoption of a participative approach has a positive effect on subordinates' satisfaction and performance.

\section{Supportive Leadership Style as a Tool}

House (2004) defined supportive leadership behavior as an emotional support of subordinates. House and Dessler (1974) also added that supportive behavior explains leaders' encouragement and friendly attitude by understanding and responding to subordinates needs and wants. This tool can be adopted by learning leaders to motivate subordinates through building strong emotional bond with them, supporting their learning attitude, and improving trust relationship with them. This supportive tool can also be used to increase subordinates' self-confidence that help subordinates to achieve the learning goal. During the time of implementing learning activities, the use of supportive tool might reduce conflicts, fear of unknown, dissatisfaction, and stress among subordinates. An empirical research by Rafferty and Griffin, (2006) has supported the idea that supportive attitude "occurring when leaders express concern for, and take account of, followers' needs and preferences when making decisions" (p. 39). They also added that adopting a supportive behavior has a positive effect on job satisfaction in the workplace.

\section{Directive Leadership Style as a Tool}

House and Dessler (1974) defined directive behavior as leaders' expectations regarding the subordinates' outcomes by giving directions and instructions. This tool can be used when subordinates do not understand the learning activity or the learning goal, and how to achieve this goal. To respond to subordinates needs, directive tool can be adopted by learning leaders to motivate them through explaining the goal and procedures, providing structures, and setting the standards that they should follow to achieve the goal. Learning leaders can use this tool to encourage a learning attitude across subordinates through planning and organizing learning activities inside an organization. This tool can also be used to have a high degree of control to implement learning activities based on learning leaders' values and standards. An empirical research was conducted by Belás (2013) found that the directive leadership style is preferred by many managers and has been adopted regardless of its negative effect on subordinates' level of satisfaction and their business performance.

\section{Achievement Leadership Style as a Tool}

House and Dessler (1974) explained achievement-oriented behavior as leaders' confidence regarding their subordinates' performance and excellent achievement. Indeed, when learning leaders take into consideration their subordinates perceptions, they might need to use a different learning leadership tool. Achievement as a tool can be 
used in the case of a challenging learning activity or a challenging goal. Learning leaders who want to achieve their challenge goals usually have high expectations and set high standards for subordinates. Learning leaders can motivate subordinates by sharing responsibility, pushing for achievement, and removing obstacles.

\section{LEARNING LEADERSHIP FOR A LEARNING ORGANIZATION}

Learning leadership is identified by this paper as a combination of personal norms and values that support the continuity of learning for leaders and their subordinates. One can stress that the continuous process of learning through improving and exchanging knowledge and experiences is an essential part for learning leadership. Wronka-Pospiech (2016) stated that "the success of any organization depends largely on who manages it" (p. 51). The motivation towards employing learning leadership, as this paper suggests, is due to its potential effect on:

1. Sustaining leaders' competences and effectiveness. An empirical study conducted by Wronka-Pospiech (2016) explained key competences of a leader and suggested that the highest rated competences of leaders are their ability to create business plans, manage conflicts, communicate effectively with all stakeholders, and the confidence to face challenging tasks.

2. Creating a motivated work environment through influencing and supporting the development of subordinates' skills, knowledge, and experiences. Based on a qualitative meta-analysis study that was conducted by Nienaber, Romeike, Searle, and Schewe (2015), there is a positive relationship between building trust relationship with subordinates and the quality of their job performance.

3. Increasing the profitability of their organizations through building on their own experience and knowledge, avoiding repetitive mistakes, and improving their weaknesses. Poór, Slavic, and Berber (2015) analyzed the main leaders' competences and their effect on organizational performance like profitability and innovation. Based on their empirical result, there is a positive and significant relationship between organizations' profitability and leaders' competences like personal credibility, communication skills, and business knowledge.

This paper suggests that learning in an organization might not improve without a learning leader. According to Chong (2005), the concept of learning organization concerns not only organizational learning but also individual learning. The concept considers organization's strategies, vision, transferring knowledge, and also considers gaining new skills and knowledge by subordinates. The paper supports that, "building a learning organization is not optional work ... and should become leaders' responsibility .... Leaders should take actions first to support a learning organization" (Wen, 2014, p. 295). Therefore, this paper proposes that a learning leader is a transformational leader who is interested in transforming his/her organization to become a learning organization.

Transformational leadership was developed by Burns (1978) who described leadership as a process of making change in organizations. Transformational leadership, as identified by Nahavandi (2014), is concerned with motivating and influencing organizational employees to reform or implement a change in their organization. One empirical study (Felfe \& Schyns, 2004) examined the correlation between transformational leadership and organizational outcomes. Felfe and Schyns concluded that transformational leadership influence the organization outcomes (efficiency and satisfaction) positively. Rijial (2016) also identified transformational leaders as "change agents, who take the responsibility for revitalizing an organization" (p.19). Rajil conducted an empirical study to examine the effect of transformational leadership and organizational culture on learning organization. Rijal found that there is a positive effect of organizational culture on the development of a learning organization. Rajil also concluded that having a transformational leadership is a positive issue in an organization since it is "responsible for creating a learning environment motivating followers to perform at their best" (p.18). In addition, learning transformational leadership is not limited to leaders' competences (skills and knowledge) but goes beyond leaders' way of thinking and their attitudes towards transforming the self and the organization. To transform an organization to a learning organization, learning leaders should keep in mind the following three elements as suggested by Wen (2014):

"promote learning theory and objectives of the organization; listen to and respect for the voice of the members; generate truly shared vision and objectives and to increase funding and time for learning, by which the organization will help members improve their qualities, competitions and personal mastery". (p. 295) 
To shed light on how leaders can enhance the motivation towards organizational learning, the paper suggests that learning leadership seeks a unique behavior that is based on the continuous process of learning. Learning leadership is also based on supporting the participative approach to encourage an organization stakeholders to participate and share their knowledge. Indeed, the implementation of participative approach is vital for learning leaders who are willing to advance their competences, and to encourage learning and information flow among subordinates, which in turn would spread the learning culture across organizations. Dymock and McCarthy (2006) stressed that teamwork and employees' participation can improve organization's performance and its competitiveness. The improvement of learning process in organizations require learning leadership to adopt not only participative behavior but also to improve self-competences, learn from own experience, and implement new knowledge quickly. One empirical study (Marcketti \& Kozar, 2007) presented a case study of leadership in a small business and highlighted the important role of leaders in achieving the goal and suggested that "knowledge must be shared in order for it to create value for an organization" (p.148). A leader in Marcketti and Kozar case study stated that "I understand that I don't know everything. I learn all of the time from my employees; in areas where I am not strong my team fills in for me" (p. 148). A leader also "invites academics from the local university .... [and] financially assists employees in attending conferences and seminars" (Marcketti \& Kozar 2007, p. 150).

In addition, learning leadership and leading by example might influence subordinates learning attitudes, which in turn would enhance their learning ability. A theoretical study was conducted by Tears and Jordan (2005) has highlighted the processes of promoting change inside organizations through leading by example. They stressed the importance of leading by example to influence organizational culture. Leading by example (being a role model) might not only enhance ongoing learning process, but also can shape the organizational learning ability and the organizational learning culture. Arguably, the continuous improvement is the base and essential partner for both learning leadership and learning organization.

\section{CLOSING}

The above discussion highlights the importance of answering how leaders can enhance the motivation towards organizational learning. The paper answers the question by suggesting points of 'setting a learning vision, enhancing subordinates' competences, encouraging participation, and being a role model' as an influence process for learning leaders in improving a learning organization.

The practice of learning leadership starts by having a learning vision to promote leaders learning values. Learning leaders are supposed to have a learning vision that identifies long-term learning goals and the ability to know how to achieve these goals. Having a learning vision is the first step, but the other recommended points (competences, participation, and role model) can be implemented to enhance the movement towards learning in organizations. But having a learning vision is only part of the transformation process. This process requires not only improving leaderssubordinates' competences, but also developing participative and teamwork behavior to serve the purpose of sustaining a learning attitude. Indeed, the responsibility of learning leaders is to influence teamwork ability among subordinates, and enhance the habits of cooperation and coordination. In addition, to motivate others for doing so, learning leaders should behave as a role model. Being a role model is critical to improve learning leaders' credibility and to support the learning vision. According to Nahavandi (2015), "the capacity to be inspiring and competent are the pillars of a leader's credibility" (p. 316).

However, the effectiveness of learning leadership can be enhanced by eliminating the barriers of learning. This paper proposes some of these barriers like hiding information by organizational stakeholders. Some still believe in information power, and how hiding information can increase their power within an organization.

\section{AUTHOR BIOGRAPHY}

Bayan Yousef Farhan is an assistant professor of management at Al Ain University of Science and Technology, UAE. She completed her doctorate in Leadership at the University of Calgary, Alberta, Canada, 2015. Before joining the University of Calgary, Dr. Farhan completed her MA and BA (Honours) at McMaster University, Ontario, Canada, 2010. In addition to leadership and strategic management, her research focus is on competition and marketization of Higher Education. 


\section{REFERENCES}

Burns, J. M. (1978). Leadership. New York: Harper \& Row

Belás, J. (2013). The leadership style and the productiveness of employees in the banking sector in Slovakia. Journal of Competitiveness, 5(1) doi:http://dx.doi.org/10.7441/joc.2013.01.03

Chong, T. A. (2005). The synergies of the learning organization, visual factory management, and on-the-job training. Performance Improvement, 44(7), 15-20.

Copland, M. A. and Knapp, M. S. (2006). Connecting leadership with learning: A framework for reflection, planning, and action. Association for Supervision and Curriculum Development. USA. PAPERBACK ISBN-13: 978-1-4166-0404-4

DeCaro, N. E. (2005). An investigation of the relationship of initiating structure, *consideration and gender perception: An examination of the path -goal theory. Retrieved from http://search.proquest.com/docview/305364782?accountid=130846

Dixon, M. L., \& Hart, L. K. (2010). The impact of path-goal leadership styles on work group effectiveness and turnover intention. Journal of Managerial Issues, 22(1), 52-69.

Dymock, D., \& McCarthy, C. (2006). Towards a learning organization? Employee perceptions. The Learning Organization, 13(5), 525-474. doi:http://dx.doi.org/10.1108/09696470610680017

Fauske, J. R., \& Raybould, R. (2005). Organizational learning theory in schools. Journal of Educational Administration, 43(1), $22-40$.

Felfe, J., \& Schyns, B. (2004). Is similarity in leadership related to organizational outcomes? The case of transformational leadership. Journal of Leadership \& Organizational Studies, 10(4), 92-102.

Ford, R. (2006). Organizational learning, change and power: Toward a practice-theory framework. The Learning Organization $13(5), 495-524$.

Hendry, C. (1996). Understanding and creating whole organizational change through learning theory. Human Relations, 49(5), 621.

House, R. J. (1971). A path goal theory of leader effectiveness. Administrative Science Quarterly, 16(3), 321-338.

House, R. J. (2004). Leadership culture and organization. California: Sage.

House, R. J., \& Dessler, G. (1974). The path goal theory of leadership: A theoretical and empirical analysis. In Schriesheim, C., \& Von Glinow, M. A. (1977). The path-goal theory of leadership: A theoretical and empirical analysis. Academy of Management Journal (Pre-1986), 20(3), 398.

Hussain, M., \& Hassan, H. (2016). The leadership styles dilemma in the business world. International Journal of Organizational Leadership, 5(4), 411-425.

Juceviciene, P. (2015). Looking for the conceptual basis of staff learning and knowledge creation at public institutions: Questioning the Dewey's theory. Viesoji Politika Ir Administravimas, 14(1) Retrieved from https://search.proquest.com/docview/1677568086?accountid=130846

Kolb, D. A. (1984). Experietial learning: Experience as the source of learning and development. Englewood Cliffs, NJ: Prentice-Hall.

Kramlinger, T. (1992). Training's role in a learning organization. Training, 29(7), 46.

Linski III, C. M. (2014). Transitioning to participative management. Organization Development Journal, 32(3), 17-26.

Malik, S. H., Aziz, S., \& Hassan, H. (2014). Leadership behavior and acceptance of leaders by subordinates: Application of path goal theory in telecom sector. International Journal of Trade, Economics and Finance, 5(2), 170-175. doi:http://dx.doi.org/10.7763/IJTEF.2014.V5.364

Marcketti, S. B., \& Kozar, J. M. (2007). Leading with relationships: A small firm example. The Learning Organization, 14(2), 142-154. doi:http://dx.doi.org/10.1108/09696470710727005

Nahavandi, A. (2014). The Art and Science of Leadership, 7th ed., Prentice Hall.

Nasima Mohamed, H. C., \& Johan, S. B. (2013). Creating a learning climate: A South African study. The Learning Organization, 20(1), 6-19. doi:http://dx.doi.org/10.1108/09696471311288492

Nienaber, A., Romeike, P. D., Searle, R., \& Schewe, G. (2015). A qualitative meta-analysis of trust in supervisor-subordinate relationships. Journal of Managerial Psychology, 30(5), 507-534.

O'Boyle, I., \& Cummins, P. (2013). Examining theories of individual performance management. Training \& Management Development Methods, 27(5), 369-377.

Ojo, O. (2009). Leadership behaviour and organisation transformation: A theoretical and empirical analysis. Universitatii Bucuresti. Analele.Seria Stiinte Economice Si Administrative, 3, 185-199.

Pei-Lee, T., \& Sun, H. (2012). Knowledge sharing, job attitudes and organisational citizenship behaviour. Industrial Management \& Data Systems, 112(1), 64-82. doi:http://dx.doi.org/10.1108/02635571211193644

Poór, J., Slavic, A., \& Berber, N. (2015). The competences of HR managers and their impact on the organizational success of MNCs' subsidiaries in the CEE region. Central European Business Review, 4(1), 5-13.

Rafferty, A. E., \& Griffin, M. A. (2006). Refining individualized consideration: Distinguishing developmental leadership and supportive leadership. Journal of Occupational and Organizational Psychology, 79, 37-61.

Rijal, S. (2016). Leadership style and organizational culture in learning organization: A comparative study. International Journal of Management \& Information Systems (Online), 20(2), 17-27. 
Sarti, D. (2014). Leadership styles to engage employees: Evidence from human service organizations in Italy. Journal of Workplace Learning, 26(3), 202-216. doi:http://dx.doi.org/10.1108/JWL-09-2013-0066

Van Breda-Verduijn, H., \& Heijboer, M. (2016). Learning culture, continuous learning, organizational learning anthropologist. Industrial and Commercial Training, 48(3), 123-128.

Wen, H. (2014). The nature, characteristics and ten strategies of learning organization. The International Journal of Educational Management, 28(3), 289-298. doi:http://dx.doi.org/10.1108/IJEM-04-2013-0062

Wronka-Pospiech, M. (2016). The identification of skills and competencies for effective management in social enterprises. A managerial perspective. Management, 20(1), 40-57. doi:http://dx.doi.org/10.1515/manment-2015-0023

Xue, Y., Bradley, J., \& Liang, H. (2011). Team climate, empowering leadership, and knowledge sharing. Journal of Knowledge Management, 15(2), 299-312. doi:http://dx.doi.org/10.1108/13673271111119709 